http://dx.doi.org/10.4314/ejotmas.v7i1-2.4

\title{
GEOSPATIAL DATA AND ARTIFICIAL INTELLIGENCE TECHNOLOGIES AS INNOVATIVE COMMUNICATION TOOLS FOR QUALITY EDUCATION AND LIFELONG LEARNING
}

\author{
*Chidinma Henrietta ONWUBERE, Ph.D.
}

\begin{abstract}
The uniqueness of open and distance learning (ODL) lies in its wide reach to a large audience simultaneously in different locations. No better system than geospatial data and artificial intelligence technologies (GDAITs) can achieve this. Globally, the current trend is to use GDAITs to improve the quality of life and productivity. Education is important for any country's economy as it enhances the overall life expectancy. Application of GDAITs in educational sector, through broadcast digitization, publishing technologies will record greater achievements in the standard of learning and the literacy of populations. At certain ages in life, people develop apathy towards learning, thus, they are cut off from additional education that could provide them with lifelong learning. With GDAITs, they can be reached with quality education anywhere. Students have constraints of time, space, and finance, for acquisition of study materials. GDAITs are able to create and deploy seamless applications which can collapse these constraints and improve the learning curves of learners. This study investigates the exposure of youths to GDAITs and the influence on their learning patterns. Gerbner's cultivation theory serves as the theoretical framework. A survey of 200 undergraduate Nigerian students was conducted, using random sampling technique. Findings show that Nigerian youths are highly exposed to GDAITs. THw paper concludes that GDAITs contribute positively and negatively to development in diverse human activities. However, it is highly effective in fostering communication education and research in Nigeria. It recommended that information and communication technology should be taught at all levels of education, so that Nigerians can develop critical minds to distinguish what GDAITs can and cannot do. Media houses should continue to establish platforms to check fake news emanating from social media. Also, attention needs to be focused on
\end{abstract}

${ }^{*}$ Chidinma Henrietta ONWUBERE, Ph.D. is of the National Open University of Nigeria, Abuja, Nigeria

Email: conwubere@noun.edu.ng 
media content to ensure that there are enough programmes that would enhance communication education in Nigeria, without fake news parasitism.

Keywords: GDAITs, Communication education, Learning processes, Social media, Digitization

\section{Introduction}

Education is important for any country's economy as it enhances the overall life expectancy. The application of geospatial data and artificial intelligence technologies (GDAITs) in the educational sector, through broadcast digitization, digital libraries, publishing technologies, etc., will record greater achievements in the standard and depth of learning as well as the literacy levels of populations. At certain ages in life, people tend to develop apathy towards learning, thus, they are cutoff from additional education that would provide them with lifelong learning. With the use of GDAITs, they can be reached with quality education at their comfort zones. These GDAITs are infotech equipment voraciously and vicariously used by the mass media to achieve the massive dissemination of information through messages, lecture materials and classified documents. They spread information across board thus availing the populace the information required for making informed decisions about their life processes and thus, the opportunity to achieve quality lifelong learning that would enhance life expectancies. In this way, the mass media exert very powerful influence in shaping our lives as we have to depend on them for information, advertisements and entertainment.

The great breakthroughs in information and communication technology in the 21st century led to the proliferation of the new media which have facilitated the creation of the different platforms for social interaction with boundless potentials as regards interactions, interrelationships, and information sharing and exchange (Adaja \& Ayodele (2013, p.1). Through social media, Nigerian youths can create, access, and disseminate any kind of information. Undoubtedly, their exposure to the messages accessed through geospatial data has some influence on their attitudes towards people around them since, according to George Gerbner's cultivation theory and Bandura's observational learning theory; the youths cultivate attitudes likened to what they learn from the mass media (Bandura, 1983). But the cultivated attitudes can impact both positively and negatively on people's ideas. This study investigates the relationship between the exposure of Nigerian youths to geospatial data and artificial intelligence technologies and their perception of social relations. The results 
obtained will be juxtaposed against the efficacy of broadcast digitization in enhancing communication education. Through digitization, seamless barrages of lectures can be streamed online for students to access effortlessly and at very minimal costs. This will greatly enhance the students' academic output, duration of their academic programmes and quality of learning. This invariably translates into enhanced lifelong learning.

\section{Broadcast Digitization}

Education in general, and communication education in particular involves lectures and consultations (searching, retrieval and exploitation) of study materials (text, image, audio, video) conveyed or saved on supports such as paper, microfilms, microfiches, analogue audio and video tapes; digital supports such as electronic disks (diskettes, SD cards, USB keys, hard disks). Paper and analogue supports such as books, microfiches, microfilms, audio and video tapes are limited in the capacity of contents they can carry and are also bulky to move around. Some of the structures and equipment for accessing these non-digitized study materials are at a geographical distance (not online), are unmovable or slightly displaceable and costly. In their quest for communication education, students are, therefore, constrained by lack of time, space energy to move about and finance - required to acquire study materials for subsequent exploitation. Some aspiring communication students, for certain reasons, cannot physically travel out of their residences to attend lectures at study centres while others are constrained by the educational fees. The multimedia devices will come in handy in such situations. Accordingly, Sartorius (2000) pointed out that the multimedia is a very powerful information tool. In her words:

Multimedia - the combination of text, images, sound, and motion - has evolved into a powerful information tool. The growth of this medium directly related to the use of personal computers and their increased media capabilities - most notably, the Internet, which is currently one of the main outlets for multimedia communicationp. (Sartorius, 2000, p.3)

In Nigeria, many governments at various levels have been trying to alleviate the burden of distant travels and educational fees by establishing their own educational institutions and offering student bursaries and scholarships. However, their efforts lack perceived effectiveness or remarkable results, partly because educational 
infrastructures are grossly insufficient, inadequate and inelastic in the country to accommodate all applicants, and partly because of the galloping population growth rate which seems to belittle or even erase any achievement when measured by population percentage. What the educational system actually requires is a digital strategy for the higher education system. This will improve experience and increase outcomes by increasing the size of students' body, research participation, leading to enhanced brand and academic excellence.

Physical library can only stock a certain quantity of physical study materials unlike a hyperlinked digital online library with expandable memory and which anybody can access at any time and from any geographical position without getting displaced. The number of students physically present to receive lectures from a lecturer is limited by the size and equipment of the lecture room, whereas if lectures are streamed online (digitized broadcast), the lecturer can effectively practise timeless and sustainable mass communication. With the digital switch over of the broadcast media, communication students will gain more access to study materials which will enable them to improve their research processes and enhance the communication education programmes. Onwubiko (2017) quoting the NBC, pointed out that "digital switch over (DSO) is the name given to the process of changing from analogue to digital TV broadcasting while the digital television transition or analogue switch-off (ASO) is the process in which analogue television broadcasting is converted to and replaced by digital television. How consumers, especially communication students in Nigeria benefit from broadcast services is part of what this paper intends to address.

Broadcast digitization makes it possible for an unlimited number of students to receive lectures live or at a differed time, repeatedly if desired, at the students' convenience, with no loss or modification in the quality and content of the lectures. Clearer pictures, audios and videos and streaming of digital content (lessons and lectures) on the internet will draw and sustain the attention of students. Broadcast digitization is cost effective to students because they can use their already acquired internet-connected devices (phones, tablets, etc.) to access and save streamed online lectures. Digital broadcasting, according to experts, means that consumers can enjoy a wider variety of shows on multiple channels with a better quality of broadcast. It also facilitates reduced power and energy consumption, and spectrum efficiency, which brings a host of associated benefits for consumers and broadcasters. All these will enhance access to educational study materials which communication students must harness for effective training on their programmes. 
Nigeria is a major stakeholder in the global move towards broadcasting digitization. Balarabe (2013) claims that "its broadcasting sector - comprising 187 radio stations, 143 television stations, etc., is easily the largest on the African continent." Opportunely, Nigeria is at the verge of total digital switchover of the broadcast media, following International Telecommunications Union's (ITU) request that all broadcast stations should go digital by June 2017. Although Nigeria has joined the global digitization process, however, the speed of decision and implementation has not been quite impressive. Currently, some television stations in Nigeria are fully digitized. These include Channels TV, TVC and NTA Jos. Channels TV has been chosen as the case study for this work because of its staff strength, independent nature, excellent broadcasting activities and international partnerships with reputable broadcast organisations such as BBC-TV, CNN, ITN, Deutsche Welle and McNeil/Lehrer News hour. (https:// www.channelstv.com/aboutus/).

\section{A Profile of Channels TV}

In 1992, the Federal Government of Nigeria deregulated the broadcast industry of Nigeria. This led to the birth of private radio and television stations. Channels Television was one of the stations birthed as a result of that policy. Channels Television is one of Nigeria's independent television stations currently broadcasting. Licensed in 2003 and broadcasting on the UHF frequency of channel 39, it has severally been rated "Best Television Station of the Year" by the Nigerian Media Merit Award Trust (www.channelstv.com). Channels Television's bias for news has placed it well above other competitors in the Nigerian television industry. The station has bagged the 'Best Television Station of the Year' an award endowed by the Nigerian Media Merit Award Trust - eleven times in the last fourteen years (2000, 2001, 2003, 2004, 2008, 2010, 2011, 2012, 2013, 2014 \& 2015), thereby making Channels Television "the station of the decade". The company is staffed with some of the best broadcast journalists in the country, with a staff strength of about 394, some of who have received training in Europe, South Africa, the United Kingdom and the United States, and many also bagging numerous awards of different categories, nationally and internationally (www.channelstv.com).

Channels TV team has produced feature programmes, which have received commendations throughout the country; video footages of events and happenings in Nigeria, shot by Channels News crews have been used widely by reputable broadcast organisations such as BBC-TV, CNN, ITN and McNeil/Lehrer News hour. The "News at Ten" is, perhaps, the most popular and most watched news programme in 
the country, while the station has earned a reputation as an aggressive news outlet, which provides a balanced account of news coverage. Channels' mission is to produce and broadcast television programmes of quality and integrity that recognize and challenge, the intelligence and curiosity of the viewer. Having acquired these numerous awards, and with its mission statement in focus, the station becomes most suitable to be the case study of this study.

Since Channels Television is a leader in digital broadcasting in Nigeria, having digitized its operations, it enhances access to education and communication research through its easy reach to educational resources. Unarguably, one of the ways, which the distant learning institutions already employ in educating, is via the use of the broadcast media and this has proved to be an effective tool in learning. Institutions such as the National Open University of Nigeria (NOUN) and the federal and state agencies for mass education employ this medium in their facilitations; and so far it has been an effective strategy. This thus, helps educators (communication educators inclusive), to have an additional source for data collection. Also, the broadcast media air programmes containing rich information which researchers can use in the course of their research. These programmes can effectively be streamed online for the students' easy reach and use.

\section{The Research Gap/ Problem}

The analogue mode of learning requires the face to face contact of the teachers and the students, moving from one place to the other to receive lectures, carrying about heavy loads of books and other study materials and incurring heavy expenditures to access study materials and other necessary equipment. All these require excessive time and income. However, with the current digitization of the broadcast media, and the effective use of GDAITs, possibility of a freely accessible universal open archive containing all kinds of scholarly materials is today a reality. So, if these facilities are harnessed by the communication education programmes, the study or graduation time frame can be shortened and greater workload can be executed for the same study duration, therefore, making the communication education programme highly time and cost effective. The students will acquire higher educational qualifications due to the quality education received by harnessing the digitized mode of learning. This open access further enhances communication education research through broadcast digitization by eliminating the barriers associated with sourcing materials for research projects which has been of great concern to instructors. As rightly observed by Sartorius (2000, p.2), "today, the digital revolution is cutting back human resources in favour 
of automated processes." Innovations adopted as a result of digitization are enormous and cannot be overemphasised. Experts observe that digitizatized supports such as the CD-ROM "has proven a versatile medium that allows readers to interact and customize their access to information." (Sartorius, 2000, p.2.). Concurring to this view, Beiser, (1996) in Sartorious (2000, p.3) posited that:

The advantage of this medium lies in its capability to deliver what today's hyperstimulated society demands: a high-capacity, dynamic, non-linear and multi-sensory medium. In fact, CD-ROMs are already being replaced by digital video discs (DVDs), whose storage capacity outperforms the ormer at a rate of 14 to 1 .

The Global Reach statistics (1999) reported that "ever-increasing variety of materials has been made available on the Internet, catering to the 129 million English-speaking users estimated to access the Internet in 1999." Lui (2006) concurs when he observed that "new media technologies (which include broadcast digitization) will bridge the social distance between sources of information and receivers. It brings tutors and their learners, leaders and followers closer." Digitization will allow for better flow of ideas and information at little or no cost. Broadcast digitization is, thus, one of the 'new shifts' that can enhance the course of communication education in the world today.

Physical lateness and absence at lectures will no longer have dramatic consequences on students as they can access streamed lectures in a differed mode. Students will become self-reliant and suffer less stress, reassured of not recopying wrongly taken lecture notes from course mates when they physically miss lectures. Broadcast digitization will facilitate and promote part-time studies for the working population who wish to acquire higher education in communication, while enhancing students' enrolment into the communication education programme.

This study investigates the relationship between the exposure of Nigerian youths to geospatial data and artificial intelligence technologies (GDAITs) and their perception of social relations and it juxtaposes the results with the efficacy of broadcast digitization in promoting communication education and research in Nigeria. It specifically, seeks to:

1. identify the level of exposure of Nigerian youths to GDAITs ;

2. determine their perception of social relations;. 
3. establish the relationship between the youth's consumption of messages from GDAITs and their perception of social relations;

4. investigate the relationship between the youth's demographic variables (age, gender, socio-economic background) and their exposure to GDAITs on the one hand, and their perception of social relations on the other; and

5. justapose the findings of this study with the efficacy of digitization of the broadcast medium in enhancing communication education and research in Nigeria.

In view of the forgoing the following research questions were set out to guide the investigation of the problem.

1. To what extent are Nigerian youths exposed to GDAITs and what is the level or intensity of their exposure to violent messages on social media?

2. How does the exposure of Nigerian youths to GDAITs (especially social media) affect their perception of social relations?

3. How do Nigerian youths exposed to GDAITs perceive social relations? Is it as human, personal and warm relationship, or as impersonal, electronic, distant relationship devoid of sensitivity or emotion?

4. Is there any relationship between Nigerian youths' demographic variables (age, gender and socio-economic statuses) and their exposure to GDAIT on the one hand; and their perception of social relations on the other hand?

\section{Conceptual Discourse \\ Perception Theory}

Perception is the assignment of meaning to sensory information. Burgoon and Ruffner (1978) define perception as "the process of making sense out of experience. To Corner and Hawthorn (1980), perception is "how an individual makes sense of his or her world". In their opinion, one's perception is a factor of his or her psychological dispositions, past experiences, cultural expectations and social relationships. This process of interpreting sensory information which the perception theory advocates, is quite complex. Berelson and Steiner (1964) confirm this when they stated that perception is the complex process by which people select, organize and interprete stimulation into a meaningful and coherent picture of the world. 


\section{Social Relations}

This refers to the social interactions between the different groups of people in the society. It means the modes of interaction among individuals and groups, groups and groups, individuals and individuals, etc., in the society. These modes of interaction are specifically represented by the polar opposites of cooperationand conflict. According to Engle and Snellgrove (1979), social interaction includes: helping or not helping others, working with others. It also involves competing as well as cooperating with people. For the purpose of this study, social relations refers to the propensity of Nigerian youths to cooperate, compete or conflict with one another or other groups of people they interact with, within the society based on the experiences from the use of the social media.

\section{Theoretical Frameworks}

The basic mass communication theories of interest are : the cultivation theory and technological determinism theory. First, the cultivation theory considers the way the excessive exposure to the media, especially through the television and other interactive media subtly shapes the users' views of the world and social reality. This theory was initially presented by George Gerbner and his associates. Some concepts emerged with the cultivation hypothesis. The major one being the mainstreaming effect. This means the "homogenization of people's divergent perceptions of social reality into a convergent mainstream" (Harris, 1994). Others include the mean-world syndrome, commonality of worldview and the-middle-of the road-view. The theory posits that viewers learn "facts about the real world through observing the world of television" The viewer automatically stores memory traces got from the television and later uses the stored information to formulate beliefs about the real world. The concrete base behind this cultivation theory is that: the more viewers watch television, the more their faith in the television version of reality. (Gerbner \& Gross, 1976).

Second, this study is hinged on the technological determinism theory as propounded by Thorstein Veblen (1857-1929), an American social scientist. The theory revolves around the proposition that technology in any given society defines its nature. Technology is viewed as the driving force of culture in a society and it determines its course of history. Karl Marx believed that technological progress leads to newer ways of production in a society and this ultimately influences the cultural, political and economic aspects of a society, thereby inevitably changing society itself. Hence, technological determiism is said to be a reductionist theory that presumes that a soceity's technology drives the deveolpment and nature of its social structure 
and cultural values. This can be felt in today's world, follwing the use of geospatial data and artificial intelligence tehcnologies.

\section{Method of Study}

The study adopted the survey research design. The population of the study consisted of undergraduates of Nigerian Universities. However, the sample was drawn from undergraduates of the National Open University of Nigeria (NOUN), which is a mega university in the Federal Capital Territory (FCT) of Nigeria. This university was purposively selected for the study for two reasons. First, it is the largest in the country, with 85 academic and vocational programmes, 78 study centres spatially situated all over the federation, and a total number of 525,000 self-learners. So, it has a wide range of students presumed to be familiar with the tools of communication and the different social networks. Second, the researcher has access to all the students' registration documents that enabled scientific selection of respondents. Through online survey monkey platform, copies of questionnaire were distributed to 200 respondents using a simple random sampling method. However, only 130 responses were received for analysis.

\section{Presentation and Analysis of Data}

The survey questionnaire comprising 20 questions was designed to provide answers to the 4 main research questions which were further fragmented and expanded into 8 questionsso as to obtain more detailed answers. Hence, for every research question, one or more corresponding survey questions were asked such that the survey responses will reinforce each other to make the answers to the research questions very reliable.

\section{Research question 1}

"To what extent are Nigerian youths exposed to geospatial data and artificial intelligence technologies (GDAITs) and what is the level or intensity of their exposure to violent messages on social media?" 
Table 1 : Do you use a smart phone of your own?

\begin{tabular}{|c|c|c|c|}
\hline Answer choices & Frequency & Percentage (\%) & Response \\
\hline Yes & 125 & 99.21 & Responded: 126 \\
\hline No & 1 & 0.79 & Skipped: \\
\hline Total & 126 & 100 & 130 \\
\hline
\end{tabular}

Result shows that $99.2 \%$, that is, 125 of 126 respondents use their own smartphones while $0.79 \%$ of them do not.

Table 2 : How often do you use your phone for these functions?

\begin{tabular}{|l|l|l|l|}
\hline Answer choices & Frequency & Percentage (\%) & Response \\
\hline $\begin{array}{l}\text { No day of the } \\
\text { week }\end{array}$ & 6 & 4.69 & Responded: 128 \\
\hline $\begin{array}{l}\text { One to three } \\
\text { days a week }\end{array}$ & 13 & 10.16 & Skipped: 2 \\
\hline $\begin{array}{l}\text { Four to six days } \\
\text { a week }\end{array}$ & 21 & 16.41 & \\
\hline Seven days & 88 & 68.75 & \\
\hline \multicolumn{1}{|c|}{ Total } & 128 & 100 & 130 \\
\hline
\end{tabular}

Again, $68.8 \%$ (88 of 128 ) use their smartphones 7 days a week, while $43.3 \%$ (55 of 127 ) spend 4 or more hours in performing their activities on their smartphone.

Table 3 : What are some of the programmes you access on your smart phone or you use smart phone for? (More than one answer may be given)

\begin{tabular}{|l|l|l|l|}
\hline Answer choices & Frequency & Percentage (\%) & Response \\
\hline Information sourcing/ news cast & 116 & 90.63 & Responded: 128 \\
\hline Message delivery & 96 & 75.00 & Skipped: 2 \\
\hline Movies & 50 & 39.06 & \\
\hline Documentaries & 56 & 43.75 & \\
\hline Musical shows & 36 & 28.13 & \\
\hline Gossip/Gists & 36 & 28.13 & \\
\hline Educational programs/tips & 97 & 75.78 & \\
\hline Cartoons & 19 & 14.84 & \\
\hline Sports & 40 & 41.25 & \\
\hline.. & 2 & 1.56 & \\
\hline Other (please specifu) & 21 & 16.41 & \\
\hline \multicolumn{1}{|c|}{ Total } & 128 & & \\
& & & 130 \\
\hline
\end{tabular}


The 3 activities most often performed with their smartphones are information sourcing/news cast $90.6 \%$ (116 of128), educational programmes/tips $75.8 \%$ (97), and message delivery 75\% (90).

Table 4 : Do some of the programme(s) you subscribe to contain violent acts and violentverbal exchanges?

\begin{tabular}{|l|l|l|lc|}
\hline Answer choices & Frequency & Percentage (\%) & Response \\
\hline Yes & 67 & 53.17 & Responded: 126 \\
\hline No & 59 & 46.83 & Skipped: $\quad 4$ \\
\hline & 126 & 100 & \multicolumn{1}{|c|}{130} \\
\hline
\end{tabular}

A total of $53.2 \%$ (67 of 126 ) agree that some of the programmes they subscribe to contain violent acts and violent verbal exchanges

\section{Data interpretation and answer to research question 1}

Given the fact that practically all respondents have permanent access to a smartphone that a majority of them use everyday for at least 4 hours for about half of respondents, mainly for information sourcing/ news cast, educational programmes/tips and message delivery especially on Whatsapp, Internet and Facebook, from local and foreign sources, it is clear that Nigerian youths are fully exposed to GDAITs and at high intensity, Whatsapp and Facebook being the greatest providers of information traffic on internet.

\section{Research question 2}

"How does the exposure of Nigerian youths to GDAITs (especially social media) affect their perception of social relations?"

Data analysis: from the 7 corresponding survey questions (11, 12, $14,15,16,18$ 19), these results were obtained:

Table 5: Members of the society are always fighting over one thing or the other

\begin{tabular}{|l|l|l|l|}
\hline Answer choices & Frequency & Percentage (\%) & Response \\
\hline Strongly agree & 60 & 47.62 & Responded: 126 \\
\hline Agree & 52 & 41.27 & Skipped: 4 \\
\hline Undecided & 8 & 6.35 & \\
\hline Disagree & 5 & 3.97 & \\
\hline Strongly disagree & 1 & 0.79 & \\
\hline \multicolumn{1}{|c|}{ Total } & 126 & 100 & 130 \\
\hline
\end{tabular}


Result also shows that $88.9 \%$ (112 of 126) perceive that members of the society are always fighting over one thing or the other

Table 6: Members of my family disagree with one another most of the time

\begin{tabular}{|l|l|l|l|}
\hline Answer choices & Frequency & Percentage (\%) & Response \\
\hline Strongly agree & 13 & 10.32 & Responded: 126 \\
\hline Agree & 51 & 40.48 & Skipped: 4 \\
\hline Undecided & 10 & 7.94 & \\
\hline Disagree & 35 & 27.78 & \\
\hline Strongly disagree & 17 & 13.49 & \\
\hline \multicolumn{1}{|c|}{ Total } & 126 & 100 & 130 \\
\hline
\end{tabular}

Result shows $50.8 \%$ (64 of 126) agree that members of their family disagree with one another most times.

Table 7: People around me do not quarrel with one another

\begin{tabular}{|c|c|c|c|}
\hline Answer choices & Frequency & Percentage (\%) & Response \\
\hline Strongly agree & 8 & 6.35 & Responded: 126 \\
\hline Agree & 19 & 15.08 & Skipped: \\
\hline Undecided & 12 & 9.52 & \\
\hline Disagree & 69 & 54.76 & \\
\hline Strongly disagree & 18 & 14.29 & \\
\hline Total & 126 & 100 & 130 \\
\hline
\end{tabular}

Result shows $69.1 \%$ (87 of 126 ) disagree that people around them do not quarrel with one another; in other words, they perceive that people around them quarrel with one another

Table 8: People in my community say negative things about one another

\begin{tabular}{|l|l|l|l|}
\hline Answer choices & Frequency & Percentage (\%) & Response \\
\hline Strongly agree & 26 & 20.63 & Responded: 126 \\
\hline Agree & 66 & 52.38 & Skipped: 4 \\
\hline Undicided & 15 & 11.90 & \\
\hline Disagree & 14 & 11.11 & \\
\hline Strongly disagree & 5 & 3.97 & \\
\hline \multicolumn{1}{|c|}{ Total } & 126 & 100 & 130 \\
\hline
\end{tabular}


Result shows $73 \%$ (92 of 126) agree that people in their community say negative things about one another

Table 9: Conscious of how people in the society and organisations relate with one another

\begin{tabular}{|l|l|l|l|}
\hline Answer choices & Frequency & Percentage (\%) & Response \\
\hline Strongly agree & 59 & 46.83 & Responded: 126 \\
\hline Agree & 63 & 50.00 & Skipped: 4 \\
\hline Undecided & 2 & 1.59 & \\
\hline Disagree & 2 & 1.59 & \\
\hline Strongly disagree & 0 & 0.00 & \\
\hline \multicolumn{1}{|c|}{ Total } & 126 & 100 & 130 \\
\hline
\end{tabular}

Result shows $96 \%$ (112 of 126) agree that they are conscious of how people in the society and organisations relate with oneanother

\section{Data interpretation and answer to research question 2}

The fact that over half of respondents acknowledge that they notice violent acts and violent verbal exchanges in their social media programmes, that people around them always fight over one thing or the other and quarrel with one another, that people in their community say negative things about one another, that their access to social media programmes makes them more conscious of how people in the society and organisations relate with one another, that their experience of social media programmes contributes to the way they relate socially with people or organisations, makes one confirm logically that intensive exposure of Nigerian youths to GDAITs makes them more alert to violent acts and violent verbal exchanges and compels them to durably face social media violence, a situation which George Gerbner's cultivation theory predicts will prompt these youths to ultimately accept such manifestations of social media violence as being normal and the contents of the messages so true as to reproduce them, for example, fake news.

\section{Research question 3}

"How do Nigerian youths exposed to GDAIT perceive social relations? Is it as human, personal and warm relationship, or as impersonal, electronic, distant relationship devoid of sensitivity or emotion?" 


\section{Data interpretation and answer to research question 3}

Judging from tables5-9, we may safely affirm that Nigerian youths exposed to GDAITs perceive social relations as somewhat inhuman, impersonal, cold, electronic and as distant relationship devoid of sensitivity or emotion for the following reasons which emerged from the survey data:

- a majority of respondents witnessed unfriendly social relations on social media.

- $\quad$ bad news and gossips sell better as news, so, they are the pices of information mostly shared on social media platforms.

- geographical distance separating interlocutors and hiding under anonymity protect them from violent physical response to social media aggression.

- $\quad$ youths' preference for text messaging rather than voice calls because of their ease and speed of communicating by text message on smartphone, as against older Nigerians who cherish direct personal and warm voice calls to relatives and friends.

- $\quad$ on smartphone, the forward to function key used by social media as strategy to communicate fast and wide discourages personal input to information received before sharing it, making social relations rather cold and mere distant electronic communication.

- $\quad$ ease and efficiency of mobilising and rallying people for political or social activism, using social media applications.

- $\quad$ ease and success of using social media platforms for online petitioning and opinion surveys boost the instrumentalisation or weaponisation of social relations at the expense of sincere human contact without which almost no socialisation was feasible before the advent of GDAITs.

\section{Research question 4}

"Do youths exposed to GDAITs perceive social relations positively or negatively?"

Data analysis: from the 6 corresponding survey questions (11, 12, $14,15,16,17)$, these results were obtained: 
Table 10: Do some of the programme(s) you subscribe to contain violent acts and violent verbal exchange?

\begin{tabular}{|l|l|l|lc|}
\hline Answer choices & Frequency & Percentage (\%) & Response \\
\hline Yes & 67 & 53.17 & Responded: 126 \\
\hline No & 59 & 46.83 & Skipped: & 4 \\
\hline & 126 & 100 & 130 \\
\hline
\end{tabular}

Result shows $53.2 \%$ (67 of 126 ) agree that some of the programmes they subscribe to contain violent acts and violent verbal exchanges.

Table 11: If the answer to question 11 is 'yes' How much violence do the programme(s) you subscribe to contain?

\begin{tabular}{|l|l|l|l|}
\hline Answer choices & Frequency & Percentage (\%) & Response \\
\hline Very little & 34 & 37.79 & Responded: 95 \\
\hline Little & 16 & 16.84 & Skipped: 35 \\
\hline Some & 40 & 42.11 & \\
\hline A great deal & 5 & 5.26 & \\
\hline \multicolumn{1}{|c|}{ Total } & 95 & 100 & 130 \\
\hline
\end{tabular}

Table 12: Members of the society are always fighting over one thing or the other.

\begin{tabular}{|l|l|l|l|}
\hline Answer choices & Frequency & Percentage (\%) & Response \\
\hline Strongly agree & 60 & 47.62 & Responded: 126 \\
\hline Agree & 52 & 41.27 & Skipped: 4 \\
\hline Undecided & 8 & 6.35 & \\
\hline Disagree & 5 & 3.97 & \\
\hline Strongly disagree & 1 & 0.79 & \\
\hline \multicolumn{1}{|c|}{ Total } & 126 & 100 & 130 \\
\hline
\end{tabular}


Table 13: People around me do not quarrel with one another

\begin{tabular}{|c|c|c|c|}
\hline Answer choices & Frequency & Percentage (\%) & Response \\
\hline Strongly agree & 8 & 6.35 & Responded: 126 \\
\hline Agree & 19 & 15.08 & Skipped: \\
\hline Undecided & 12 & 9.52 & \\
\hline Disagree & 69 & 54.76 & \\
\hline Strongly disagree & 18 & 14.29 & \\
\hline Total & 126 & 100 & 130 \\
\hline
\end{tabular}

Table:14: People around me do not quarrel with one another

\begin{tabular}{|l|l|l|l|}
\hline Answer choices & Frequency & Percentage (\%) & Response \\
\hline Strongly agree & 8 & 6.35 & Responded: 126 \\
\hline Agree & 19 & 15.08 & Skipped: 4 \\
\hline Undecided & 12 & 9.52 & \\
\hline Disagree & 69 & 54.76 & \\
\hline Strongly disagree & 18 & 14.29 & \\
\hline \multicolumn{1}{|c|}{ Total } & 126 & 100 & 130 \\
\hline
\end{tabular}

Table 15: People in my community say negative things about one another

\begin{tabular}{|l|l|l|l|}
\hline Answer choices & Frequency & Percentage (\%) & Response \\
\hline Strongly agree & 26 & 20.63 & Responded: 126 \\
\hline Agree & 66 & 52.38 & Skipped: 4 \\
\hline Undicided & 15 & 11.90 & \\
\hline Disagree & 14 & 11.11 & \\
\hline Strongly disagree & 5 & 3.97 & \\
\hline \multicolumn{1}{|c|}{ Total } & 126 & 100 & 130 \\
\hline
\end{tabular}


Table 16: Members of my family disagree with one another most of the time

\begin{tabular}{|l|l|l|l|}
\hline Answer choices & Frequency & Percentage (\%) & Response \\
\hline Strongly agree & 13 & 10.32 & Responded: 126 \\
\hline Agree & 51 & 40.48 & Skipped: 4 \\
\hline Undecided & 10 & 7.94 & \\
\hline Disagree & 35 & 27.78 & \\
\hline Strongly disagree & 17 & 13.49 & \\
\hline \multicolumn{1}{|c|}{ Total } & 126 & 100 & 130 \\
\hline
\end{tabular}

Table 17:Conscious of how people in the society and organisations relate with one another

\begin{tabular}{|l|l|l|l|}
\hline Answer choices & Frequency & Percentage (\%) & Response \\
\hline Strongly agree & 59 & 46.83 & Responded: 126 \\
\hline Agree & 63 & 50.00 & Skipped: 4 \\
\hline Undecided & 2 & 1.59 & \\
\hline Disagree & 2 & 1.59 & \\
\hline Strongly disagree & 0 & 0.00 & \\
\hline \multicolumn{1}{|c|}{ Total } & 126 & 100 & 130 \\
\hline
\end{tabular}

\section{Data interpretation and answer to research question 4}

Judging from tables 10-17, the total concordance among survey results which in majority present social relations on social media as negative shows that youths exposed to GDAIT perceive social relations negatively.

\section{Discussion of Findings}

\section{Consequencies of GDAITs for Small Infrastructure Countries such as Nigeria}

The survey data analysed revealed that GDAITs have incidence on small infrastructure countries such as Nigeria. This concerns the sociocultural, political and economic consequencies of the exposure of Nigerian youths to GDAITs, having in mind that Nigeria as a small infrastructure country lacks effective means to curb or control the negative influences of these technologies on its people and society. Electronic media contents developed with geospatial data and artificial intelligence (text, photo, audio, video and programmes) are accessed and disseminated by youths through social media and online 
applications such as Facebook, Whatsapp, Instagram, Twitter, YouTube, Imo, Mobile TV. These platforms unwittingly propagate fake news, hate speeches, audiovisual manipulations and falsifications aimed at building conspirational theories or skewed points of view which may promote insurgency, ethno-religious and personal hatred, political propaganda and radicalism leading to terrorism and other forms of gratuitous violent acts and aggressions. Several authors have identified social media as the 'oxygen' for radicalisation. Confirming this view, Lemack and Hall (2013) consider the Internet as the singlemost important and dangerous innovation since the terrorist attacks of September 11, 2001.

The study indicates that Nigerian youths use GDAITs voraciously in almost all their lives activities. Since these emerging technologies have eliminated the financial, spatial and temporal (time) barriers formerly existing between the acquisition of print and electronic media, the nature and content of what is consumed and spread as external information have radically changed and escalated. Consequently, there is upsurge of youthful exuberances, as youths can easily publish and widely express themselves positively or negatively through these electronic media, unfettered by the financial and editing constraints hitherto imposed on writers and producers who use the conventional publishing companies and channels. With today's information communication technologies using geospatial data and artificial intelligence, audios, videos, photos and texts can be produced, updated and uploaded to the internet for mass consumption in record time. This increases the pace and contents of gainful developments in diverse sectors of human activity. Conversely, however, these laudable technologies also permit the pollution of minds and disruption of social relations in record time because social media has expanded public reach and has thus become a tremendous outreach tool that can widely disseminate any issue of public concern and give it an unprecedented level of broadcast. Scholars have confirmed that a lot of violence is incorporated into circulated mass media messages and programmes (Singer \& Singer 2001). As Sylwester (2001) and Demnievska (2018) rightly observed, the computer age has revolutionalised the mass media and this is a kind of cultural revolution amongst the youths.

This article posits that this revolutionisation of the computer age will generously enhance communication education and research if positively applied and that the same effect recorded on the youths' perception of social relations can translate to their access to quality education for lifelong learning through the use of GDAITs. Social media consumption patterns may affect learning outcomes for self-learners; bearing in mind that fake news phenomenon leads to misinformation. 
Learners should therefore not rely only on information received from the social media but delve deeper to search for true and valid information for proper learning. Rather than mainly using GDAIT to propergate fake news, they will use them as veritable educational tools that will enhance their academic programmes

\section{Conclusion}

GDAITs contribute positively and negatively to development in diverse sectors of human activity. In small infrastructure countries with little or no suitable means to fight the bad influence, the latter appears to defeat the joys brought by the good influence. Since we cannot arrest progress, we recommend the following measures to temper the negative influence:

- $\quad$ students in tertiary education are the future leaders, and over $65 \%$ of the voting population in Nigeria are youths who are often inadvertent victims of suble manipulations through fake news in all its ramifications. So, to secure Nigerias's future, it is imperative to continue to evolve more effective ways to fight fake news to the barest minimum as it is the main culprit in the disadvantages of GDAITs. Culprits caught should be punished decisively to deter would-be culprits;

- use of information and communication technology should be taught at all levels of education so that Nigerians can develop critical minds to distinguish what GDAITs can and cannot do; and

- mainstream media houses and agencies should continue to establish platforms to check fake news emanating from social media.

Based on the responses of some sampled professionals, a majority of the respondents generally agreed that Channels TV has contributed towards the development of communication education, and that digitization will enhance communication research, but then they disagree with the efficacy of digitization because of lack of adequate programs relating to communication education research on the broadcast media. The findings of this study clearly show that digitization will improve viewership and consequently communication education and research. This is further proven using the case study of this work, 'Channels TV', which shows that digitization offers clearer images and sounds; provides platform for information on communication education research and also allows for greater interactivity than with the analogue media programmes.

In justaposing the results of the study on digitization of the broadcast medium and based on the responses of the sampled 
professionals, a majority of the respondents generally agreed that Channels TV has contributed towards the development of communication education, and that digitization will enhance communication research, but then they advised that adequate programmes relating to communication education research should be streamed on the broadcast media to further enhance the efficacy of digitization for communiction education and research. The findings of this paper clearly show that digitization will improve viewership and consequently communication education and research. . However, attention needs be focused on the media content to ensure that there are enough programmes that would enhance communication education generally and specifically, communication education research in Nigeria, without fake news parasitism.

\section{References}

Adaja, T.A. \& Ayodele, F.A (2013). Nigerian youths and social media: Harnessing the potentials for academic excellence. Kuwait Chapter of Arabian Journal of Business and Management Review, 2(5), 1-13.

Balarabe, S (2013).Digitization of television broadcasting in Nigeria. International Journal of Information and Communication Engineering, 2, 1-11.

Bandura, A. (1994). Social cognitive theory of mass communication. In J. Bryant \& D. Zilman (Eds). Media effects: Advances in theory and research (pp. 61-90). Hillsdale; NJ: Erlbaum.

Beiser, K. (1996). CD-ROM - the year ahead. Technology Online, 20(1), 90-94.

Blakeney, P. (1993, November/ December). The plant floor multimedia connection. Computer Pictures, 11(6) [advertising supplement], 3.

Berelson, B. \& Steiner, G. A. (1964). Human behaviour: An inventory of scientific findings. New York: Harcourt Bruce and World.

Burgoon, M. \& Ruffner, M. (1978). Human communication : Introduction. New Jersey: Holt, Rinehart.

Corner, J. \& Hawthorn, J. (1980). Communication studies. An introductory reader. London: Edward Arnold.

Demnievska, E. (2018). The UNESCO Courier o July-September 2018 | 3,pp1-72

Engle, T.L and Snellgrove, L. (1979). Psychology: It principles and applications. New York: Harcourt Bruce.

Global Reach (1999, September 26). Global internet statistics (by language). Retrieved 23 August 2019, from http:// glreach.com/globstats/. 
Gerbner, G. \& Gross L, (1976) in in Onwubere, C.H(2012). Exposure of Nigerian children to television and video violence and their perception of social relation. Saarbrücken: Lambert Academic Publishing GmbH \& Co KG.

Gerbner, G., Gross, L, Morgan, M., and Signorelli, N. (1994). Growing up with television: The cultivation perspective, in Onwubere, C.H (2012). Exposure of Nigerian children to television and video violence and their perception of social relation. Saarbrücken: Lambert Academic Publishing GmbH \& co KG.

Lemack, Hall (2013) cited in Siraj O. A. (2017). Social media and social vices: Curtailing youthviolent extremism through mil strategies. A paper presented at UNESCO workshop ontraining of trainers on media and information literacy, Tuesday,18th July, 2017.

Liu, C. (2006) De-skilling effects on journalists: ICTs and the labour process. Taiwan: Chung Cheng University.

Onwubiko, E. (2017). Digitization of broadcasting: Any progress? The Sun Newspaper, 12th November 2017.

Sartorius, U. (2000). Digitization and graphic communication education: From print reproduction to dynamic image generation. Journal of Industrial Technology, 16(2), 1-9.

Singer, D.G. \& Singer, J. L. (2001). Handbook of children and the media. London:Sage.

Skillings, J. (2006). Getting machines to think like us. CNet News. Retrieved 23 December 2018, from http://news.cnet.com/ Getting-ma ...

Sylwester, R. (2001). How mass media affect our perception of reality. A monthly column by sylwester@brainconnection.com. 